\title{
Unjustified Referral of Adult Patients with Hypertensive Crisis from a First Level of Care to the Emergency Department
}

\author{
Rodriguez-Zuñiga Jorge ${ }^{1^{*}}$, Garcia-Hernandez Jorge Alfredo ${ }^{2}$ Lopez-Vilchis Lizeth \\ Liliana $^{3}$, Ruiz-Mondragon Alberto ${ }^{4}$ and Sanchez-Martinez Fatima Alondra ${ }^{4}$
}

${ }^{1}$ Emergency Medicine Department, Hospital General of Zone No 50 IMSS, San Luis Potosi, Mexico

${ }^{2}$ Clinical Coordination of Education and Health Research, Hospital General of Zone No 50 IMSS, San Luis Potosi, Mexico

${ }^{3}$ Emergency Medicine Department, Hospital General of Zone No 1 IMSS, San Luis Potosi, Mexico

${ }^{4}$ Professor of the Residency in Emergency Medicine, Hospital General of Zone No 50 IMSS, San Luis Potosi, Mexico

*Corresponding author: Jorge Rodriguez Zuñiga, Department of Emergency Medicine, Hospital General of Zone No 50 IMSS, Av Tangamanga 205 Prados de San Vicente, San Luis Potosi, Mexico, Tel: +52-868-175-9305

\begin{abstract}
Introduction: Hypertensive crisis is one of the main complications of systemic arterial hypertension, which is defined as severe elevation of blood pressure, with figures of more than $220 / 130 \mathrm{mmHg}$, these in turn are divided into urgency and emergency, which occurs when there is damage to a target organ. According to the literature, the majority of hypertensive crises that occur are of an urgency type, reported in up to $80 \%$ of cases, the latter do not require a rapid decrease in blood pressure, taking up to 72 hours to control them, so they must be treated in a first-level care unit, however, a high number of referrals to the emergency department for hypertensive crisis of an urgency type have been detected, which have no justification for their referral.
\end{abstract}

Primary objective: To determine the frequency of unjustified referrals of adult patients with hypertensive crisis to the emergency department of a second-level hospital.

Methods: Observational, cross-sectional, descriptive study, non-probability sampling type, Sample size calculated based on the finite population formula. Patients referred from the first-level units in the period of august 2019 to July 2020 with a diagnosis of hypertensive crisis were included, where the reason for referral to the emergency service was determined in addition to the clinical characteristics of the patient, blood pressure figure, in addition to determine if it is a hypertensive urgency or emergency (in this case evaluating acute target organ damage).

Results: Of the 204 referrals, the majority were hypertensive urgencies with $161(78.9 \%)$ and $43(21.1 \%)$ were emergencies, 119 women $(58.3 \%)$ and 85 men $(41.7 \%)$, Regarding the referrals for hypertensive emergencies (43 referrals), which correspond to $21.1 \%$ of the total number of patients, we observed that the most frequent was acute coronary ischemic syndrome with 13 patients $(30.2 \%)$, followed by acute pulmonary edema with 12 patients $(27.9 \%)$, the one with the lowest prevalence was acute kidney injury with only 4 patients, corresponding to $9.3 \%$. Additionally, it was found that in the vast majority of cases of both urgency and hypertensive emergency, patients did not adhere to their usual treatment in a similar percentage, $131(81.4 \%)$ for urgencies and $34(79.1 \%)$ for emergencies.

Conclusions: In this study, referrals for hypertensive crisis from the first level units to the emergency department of our hospital were not justified in $78.9 \%$ of the cases.

The prevalence of hypertensive crisis is higher in women than in men.

Most of the patients due to urgency and hypertensive emergency $(81.4 \%$ and $79.1 \%$ respectively) do not adhere to their usual treatment.

It was observed in our study that a high percentage of patients $(18 \%$ for hypertensive emergency and $46 \%$ for hypertensive urgency) do not receive drug treatment at the primary care site.

\section{Keywords}

Hypertensive crisis, Hypertensive urgency, Hypertensive emergency, Unjustified referral, hypertension, Blood pressure treatment

\section{Abbreviations}

HTN: Hypertension; BP: Blood Pressure; MmHg: Millimeters of Mercury; NMR: Nuclear Magnetic Resonance; UO: Urine Output; GFR: Glomerular Filtration Rate; ACE Inhibitors: Angiotensin-Converting-Enzyme Inhibitors; Mg: Milligram;

Citation: Rodriguez-Zuñiga J, Garcia-Hernandez JA, Lopez-Vilchis LL, Ruiz-Mondragon A, Sanchez-Martinez FA (2021) Unjustified Referral of Adult Patients with Hypertensive Crisis from a First Level of Care to the Emergency Department. Int Arch Cardiovasc Dis 5:034. doi.org/10.23937/2643-3966/1710034 Accepted: January 21, 2021: Published: January 23, 2021

Copyright: (c) 2021 Jorge RZ, et al. This is an open-access article distributed under the terms of the Creative Commons Attribution License, which permits unrestricted use, distribution, and reproduction in any medium, provided the original author and source are credited. 
Mcg: Microgram; IMSS: Instituto Mexicano del Seguro Social; UMF: Unidad de Medicina Familiar; ARBs: Angiotensin II Receptor Blockers

\section{Introduction}

In Mexico, a high prevalence of cases of hypertension (HTN) has been maintained due to the increase in cases of essential chronic diseases such as type 2 diabetes mellitus, dyslipidemias, obesity and metabolic syndrome [1].

The 2020 Mexican clinical practice guide for the diagnosis and treatment of hypertensive crises mentions that the incidence of hypertensive crises in the world has decreased in recent years, in part due to the easy availability and use of antihypertensive drugs [1]. Different situation in our country where the rate of hypertensive crisis as well as cerebral vascular events, diabetes mellitus, chronic renal failure, ischemic heart disease, heart failure and diabetic retinopathy are increasing because according to the national survey of the year 2000, $61 \%$ of the people who were detected with HTN were unaware of being carriers of the disease, so the patient goes to the doctor after several years, during which time there will be some degree of damage to the target organ for the most part [2]. In addition to the fact that only $50 \%$ of the patients known to have the disease are under antihypertensive drug treatment, of these $14.6 \%$ showed figures lower than $140 / 90 \mathrm{mmHg}$ (Millimeters of mercury) [3].

\section{Definition}

According to the 2017 American College of Cardiology and American Heart Association guidelines, high blood pressure (BP) is considered in adult patients when the figures are $120-129 \mathrm{mmHg}$ systolic and less than 80 $\mathrm{mmHg}$ diastolic, likewise considers Hypertension stage 1 when having figures of $130-139 \mathrm{mmHg}$ for systolic or $80-89 \mathrm{mmHg}$ for diastolic and stage 2 when the figures are equal to or greater than $140 \mathrm{mmHg}$ for systolic or equal to or greater than $90 \mathrm{mmHg}$ for diastolic [4].

In the 2018 European Society of Cardiology guidelines on hypertension, hypertension is defined as a persistent elevation taken in the office with figures greater than or equal to 140 diastolic and/or greater than or equal to 90 diastolic, which is equivalent to a 24-hour ambulatory BP monitoring with figures equal to or greater than $130 / 80 \mathrm{mmHg}$, or a home BP measurement greater than or equal to $135 / 85 \mathrm{mmHg}$ [5].

Hypertensive crises are a heterogeneous group of hypertensive disorders characterized by severe hypertension and acute damage to target organs such as the brain, heart, kidney, retina, or blood vessels. BP is usually $220 / 130 \mathrm{mmHg}$ or higher, but it can be much lower in women with preeclampsia without prior hypertension [6].

\section{Pathophysiology}

A hypertensive crisis can develop de novo or as a complication of essential or secondary arterial hypertension. To date, the triggers are unclear. The rapid rise in blood pressure figures suggests the existence of a trigger factor superimposed on the already existing arterial hypertension.

Until now, it is known that the abrupt increase in vascular resistance can be the cause of a hypertensive crisis, associated with the presence of humoral vasoconstrictors. In addition to this, endothelial injury occurs secondary to mechanical stress causing increased permeability, activation of the coagulation cascade and platelets and fibrin deposits.

The arterioles suffer fibrinoid necrosis and endothelial damage from these abrupt rises in pressure. Secondary to this, ischemia and release of vasoactive mediators occurs, causing a continuous cycle of injury. There is also activation of the renin-angiotensin system causing greater vasoconstriction as well as the release of pro-inflammatory cytokines such as interleukin-6.

As there is a volume depletion secondary to this vicious cycle of endothelial damage, there is also a release of vasoconstrictive substances from the kidney, all of this resulting in hypoperfusion of target organs, causing ischemia and dysfunction of the same, to later present the classic symptoms of hypertensive emergency depending on the organ that has suffered the greatest secondary injury [7].

The characteristic of arterial hypertension is essentially due to a dysfunction of the endothelium, which in turn is accompanied by an imbalance between the factors that relax the blood vessels, which are nitric oxide and the hyperpolarizing factor of the endothelium, and the factors that promote the vasoconstriction that are endothelin.

In addition, there is a decrease in vasodepressive prostacyclin PG-12 at the endothelium level with the consequent increase in intracellular vasoconstrictor thromboxane-TXA2 [8].

\section{Clinical Manifestations}

\section{Hypertensive urgency}

In the case of urgencies, since in these there is no damage to the target organ or, if this occurs, it is mild-moderate in nature, so these should normally be treated at the first level of care with oral treatment.

In these cases, the most frequent clinical manifestations that motivate the patient to seek medical attention are usually symptoms such as:

- Headache

- Dizziness 
- Instability

- Epistaxis

Although it should be mentioned that a large percentage of these patients are asymptomatic even with high BP levels and are detected as a finding or accident.

\section{Hypertensive emergency}

The most common hypertensive emergencies according to the order of presentation frequency are: Acute left ventricular dysfunction with pulmonary edema (22\%), acute coronary syndromes (18\%), and aortic dissection (8\%).

Another variable is when there is a hypertensive crisis secondary to the misuse of sympathomimetic drugs, imitating the clinical manifestations, the most common drug is cocaine, representing one third of all reasons for emergency visits for this cause.

In the context of symptomatology, clinical manifestations are related to target organ dysfunction.

The most frequent symptoms associated with a hypertensive emergency secondary to a coronary ischemic event is chest pain, when acute pulmonary edema occurs, dyspnea may be added, in the case of hypertensive emergencies caused by cerebral vascular events or hypertensive encephalopathy, it may occur headache, sudden neurological deterioration as well as seizures or loss of alertness [9].

\section{Types of Hypertensive Emergency}

\section{Hypertensive encephalopathy}

Condition which occurs secondary to an abrupt elevation of blood pressure with the presence of clinical manifestations such as intense and progressive headache, nausea, vomiting and visual disturbances, this due to the fact that the mechanisms of autoregulation of cerebral perfusion are not capable of regulating the blood flow.

Headache may appear initially, which has been reported as intense and progressive, sometimes accompanied by nausea, vomiting, visual disturbances, the latter may or may not have retinal complications, sudden onset confusion, alterations in the consciousness, as well as seizures.

An important characteristic is that these symptoms appear progressively in the first $24-48$ hours, this allows to differentiate a picture of hypertensive encephalopathy from an intracranial hemorrhage. These symptoms disappear when there is a drop in blood pressure, however, if this sudden rise in pressure is not treated, the patient can progress to coma, with subsequent increased chances of death.

By means of nuclear magnetic resonance (NMR), posterior leukoencephalopathy can be observed, pre- dominantly in the parietal occipital region, this can be reversible by having an effective and rapid management of the elevation of pressure [9].

\section{Ischemic stroke in acute phase}

In hypertensive patients with stroke, there is a sudden rise in blood pressure and subsequently a drop within 90 minutes after the onset of symptoms. This elevation and maintenance of blood pressure also influences the maintenance of perfusion in the area known as the penumbra area, which is adjacent to the lesion, it is believed that it occurs as a physiological response to preserve blood flow.

It is recommended in stroke in case of systolic BP figures greater than or equal to $220 \mathrm{mmHg}$ and/or diastolic blood pressure equal to or greater than $120 \mathrm{mmHg}$, the figures should be reduced by $10-15 \%$ within the first 24 hours, If the patient is also a candidate for fibrinolytic treatment, antihypertensive treatment should be indicated to keep the BP below 185/110 $\mathrm{mmHg}$, the intravenous antihypertensive recommended in case of having a figure greater than $220 \mathrm{mmHg}$ of the systolic or 121$140 \mathrm{mmHg}$ of the diastolic it is labetalol, and in case of maintaining a diastolic blood pressure greater than 140 $\mathrm{mmHg}$ sodium nitroprusside [9].

\section{Intracranial hemorrhage in acute phase}

In these cases, bleeding should be reduced based on antihypertensive treatment, but always trying to preserve blood perfusion, whether it is a brain hematoma or a subarachnoid hemorrhage.

It is known that perfusion in the brain depends on intracranial pressure (ICP) and mean arterial pressure (MAP), so when ICP increases secondary to hemorrhage, the way to preserve perfusion is to keep MAP in numbers equal to or greater than $60 \mathrm{mmHg}$. A progressive decrease in pressure should be carried out when BP figures are above $180 \mathrm{mmHg}$ for systolic and above $105 \mathrm{mmHg}$ for diastolic or MAP greater than 130-150 $\mathrm{mmHg}$. In this type of hypertensive emergency, the antihypertensive treatment of choice is Labetalol as the first option, followed by sodium nitroprusside [9].

\section{Acute coronary ischemic syndrome}

Often a hypertensive emergency and a cardiac ischemia can present together, this is believed to be associated with the stress that is presented by the intense precordial pain that is generated.

The main objective in acute coronary syndrome is a decrease in the work done by the heart muscle to improve blood perfusion, these can be affected by changes in afterload, so there is a resulting ischemia secondary to the alteration of this balance of the supply and demand of oxygen.

The most common clinical finding that occurs in this 
variant is chest pain, lasting more than 20 minutes of the oppressive, transfictive type, which occurs at rest or when performing some physical activity, sometimes this pain radiates to the limb left thoracic, mandibular region, epigastrium, left scapula, in addition to being accompanied by diaphoresis, nausea and/or vomiting and syncope.

Anginal Equivalents/Atypical Pain:

- Dyspnea

- Asthenia and adynamia

- Chest discomfort

- Shooting pain in chest

- Pleuritic pain

- Syncope

- Nausea

- Feeling of anxiety or impending death

The electrocardiogram is the most important tool in the diagnosis of ST-segment elevation infarction.

The criteria for diagnosing an ST segment elevation infarction should be presented:

- $\mathrm{ST}$ segment elevation $>1 \mathrm{~mm}(0.1 \mathrm{mV})$ in 2 contiguous leads (except V2-V3 Men $>0.2 \mathrm{mV}$ in $>$ 40 years and $>0.25$ in 40 years and in women $>$ $0.15 \mathrm{mV}$ ).

- Elevation of the ST segment in posterior leads > $0.5 \mathrm{mV}$.

Another useful method in acute myocardial infarction is the use of cardiac biomarkers. It is important to mention that although these must be carried out systematically in the acute phase, they should not be a reason for delaying reperfusion treatment [10] (Table 1).

Malignant arterial hypertension with hypertensive retinopathy
Malignant arterial hypertension is actually an underdiagnosed pathology due to the lack of exploration of the fundus, however, it is of great clinical importance when hypertensive retinopathy occurs, this is secondary to the abrupt elevation of blood pressure in approximately $5-10 \%$ of the cases, it is detected when performing the ophthalmological examination finding hemorrhages and/or exudates which represent the ischemic or hemorrhagic lesion, papillary edema can also be observed [11].

\section{Aortic dissection}

It is the damage at the level of the aorta artery secondary to the excessive elevation of blood pressure, in this condition intense chest pain is usually presented which can radiate to the back, commonly characterized as acute tear-type pain, migrating towards the posterior chest in a in $90 \%$ of cases, radiation to the epigastrium can also occur in approximately $21 \%$ of cases, and this is related to compromise of vascularity at the mesentery level. Other clinical characteristics are the presence of weak or absent peripheral pulses, also finding a significant variation in the systolic blood pressure in both arms of approximately $20 \mathrm{mmHg}$, they can present to the emergency department with neurological deterioration, hypotensive or in a coma [12].

\section{Acute left ventricular dysfunction with acute pul- monary edema}

It is characterized by the presence of sudden dyspnea, polypnea, tachycardia, a characteristic cough which is referred to as salmonella, orthopnea, in addition to anxiety due to respiratory distress, when evaluating the patient, elevated blood pressure levels are detected in addition to arterial hypoxemia, Sometimes this condition is related to acute myocardial infarction, left valve insufficiency, valve dysfunction, a rapid diagnostic and therapeutic approach must be carried out to rule out the associated pathologies mentioned and reduce respiratory distress [13].

Table 1: Serum biomarkes [10].

\begin{tabular}{|l|l|l|l|}
\hline BIOMARKERS & TIME OF APPEARANCE & MAXIMUM ELEVATION PEAK & TIME OF RETURN TO NORMALITY \\
\hline CKMB & $2-3$ hours & $20-24$ hours & $48-72$ hours \\
\hline Troponin I & $3-12$ hours & 24 hours & $5-10$ days \\
\hline Troponin T & $3-12$ hours & 12 hours-2 days & $5-14$ days \\
\hline Myoglobin & $1-2$ hours & $5-7$ hours & 24 hours \\
\hline
\end{tabular}

Table 2: AKIN Classification [14].

\begin{tabular}{|c|c|c|c|}
\hline STAGE & CREATININE (MG/DL) & URINE OUTPUT (UO) (ML/KG/HR) & CATEGORY \\
\hline I & $\begin{array}{l}\mathrm{Cr} \times 1.5 \text { or } \mathrm{Cr} \text { equal to or greater than } 0.3 \text { over }<48 \\
\text { hours }\end{array}$ & $<0.5$ for 6 hours & Risk \\
\hline II & Cr increased 2-3 times or GFR & $<0.5$ for 12 hours & Injury \\
\hline III & $\begin{array}{l}\mathrm{Cr} \times 3 \text { or } \mathrm{Cr} \text { equal to or greater than } 4 \text { with an increase } \\
\text { equal to or greater than } 0.5 \text { or patients with renal } \\
\text { replacement therapy }\end{array}$ & $\begin{array}{l}<0.3 \mathrm{ml} \text { for } 24 \text { hours } \\
\text { Anuria for } 12 \text { hours }\end{array}$ & Failure \\
\hline
\end{tabular}




\section{Acute kidney injury}

It is detected after the admission of the patient with high levels of blood pressure, this can present concomitantly with other variants of hypertensive emergency, and it is detected once laboratory tests are performed or when evaluating the urinary index, detecting elevation of the nitrogen compounds or oliguria [14].

Different classifications can be used for acute kidney injury, among which is AKIN (Table 2).

\section{Diagnosis}

Initially, it is clinical, since the patient presents to the emergency department or outpatient clinic for subsequent evaluation or for presenting symptoms, it is necessary to inquire whether he has a history of arterial hypertension, the time of evolution, the treatment in case of already having one, adherence to it, as well as the use of other types of substances that can trigger hypertensive crises such as amphetamines, cocaine, monoamine oxidase inhibitors, etc.

A complete physical examination should be carried out directed towards the diagnostic suspicion, considering damage to the target organ from verifying peripheral pulses, data of pulmonary congestion, heart murmurs or gallop rhythm, murmurs in the renal fossae, perform a neurological examination in which It should include a review of the fundus, if hypertensive encephalopathy is suspected, data of headache and altered neurological status should be sought, data suggestive of a cerebrovascular event are neurological targeting or signs of lateralization, if aortic dissection is suspected when pain is present thoracic, asymmetric pulses, widened mediastinum, etc. An urgent computerized axial tomography or magnetic resonance imaging of the chest should be performed, in patients with acute pulmonary edema, an echocardiogram should be performed once the patient is stabilized [15].

\section{Treatment}

If figures are detected in the BP levels associated with damage to the target organ, a rapid initial evaluation should be carried out aimed at the suspicion of the type of hypertensive crisis that the patient presents, once the damage to the target organ is detected it should be carried out an aggressive reduction of the $\mathrm{BP}$, this due to the high risk that the patient presents in terms of complications and the high risk of death, hypertensive emergencies should be treated in a hospital setting to achieve a rapid reduction of BP figures and limit damage, these patients should be kept under continuous monitoring in an intensive care unit.

The indicated treatment is with parenteral antihypertensive drugs, these must be administered in an intensive care unit to reduce the risk of hypoperfusion of the cerebral, coronary and renal beds, as well as to control organic damage [15] (Table 3).
Initial management will depend on the type of hypertensive crisis that occurs, if systolic pressure figures of $160 \mathrm{mmHg}$ or diastolic pressure of $110 \mathrm{mmHg}$ are detected without presenting any symptoms, it is determined as a hypertensive urgency, the ideal management of these patients is with antihypertensive oral with a decrease in the figures in a period of 24 to 48 hours, these patients should be treated at the first level of care with an initial monitoring of the patient and subsequently, outpatient treatment with an appointment for subsequent evaluation. In the event of a rapid reduction in $\mathrm{BP}$, it may be associated with an increase in patient morbidity, secondary to the deviation to the right of the pressure/flow autoregulation curve in critical arterial beds such as the cerebral, coronary and renal beds. Therefore, the figures should be reduced in a slow and controlled manner to avoid the presence of organic hypoperfusion [16] (Table 4).

Table 3: Drugs used in the treatment of hypertensive emergency [15].

\begin{tabular}{|c|c|}
\hline DRUG & DOSE \\
\hline Sodium nitroprusside & $\begin{array}{l}\text { Infusion of } 0.25 \mathrm{mg} / \mathrm{kg} / \mathrm{minute} \text { up to } \\
10 \mathrm{mcg} / \mathrm{kg} / \text { minute, or until reaching } \\
\text { the appropriate BP figure. }\end{array}$ \\
\hline Nicardipine & $\begin{array}{l}5 \mathrm{mg} / \text { hour, increase by } 1-2.5 \mathrm{mg} / \\
\text { hour every } 15 \mathrm{~min} \text {, maximum dose } \\
10 \mathrm{mg} / \text { hour }\end{array}$ \\
\hline Labetalol & $\begin{array}{l}1 \text { to } 2 \mathrm{mg} / \mathrm{min} \text {, or } 20 \text { to } 80 \mathrm{mg} \mathrm{IV} \\
\text { bolus every } 5 \text { to } 10 \mathrm{~min} \text {, increase to } \\
300 \mathrm{mg} \text { of total dose }\end{array}$ \\
\hline Esmolol & $\begin{array}{l}0.5 \text { to } 1 \mathrm{mg} / \mathrm{kg} \text { loading dose over } 1 \\
\text { minute, followed by infusion starting } \\
\text { at } 50-300 \mathrm{mcg} / \mathrm{kg} / \mathrm{min}\end{array}$ \\
\hline Nitroglycerin & Infusion 5 a $200 \mathrm{mcg} / \mathrm{min}$ \\
\hline
\end{tabular}

Table 4: First-line drugs in the treatment of hypertensive urgency [16].

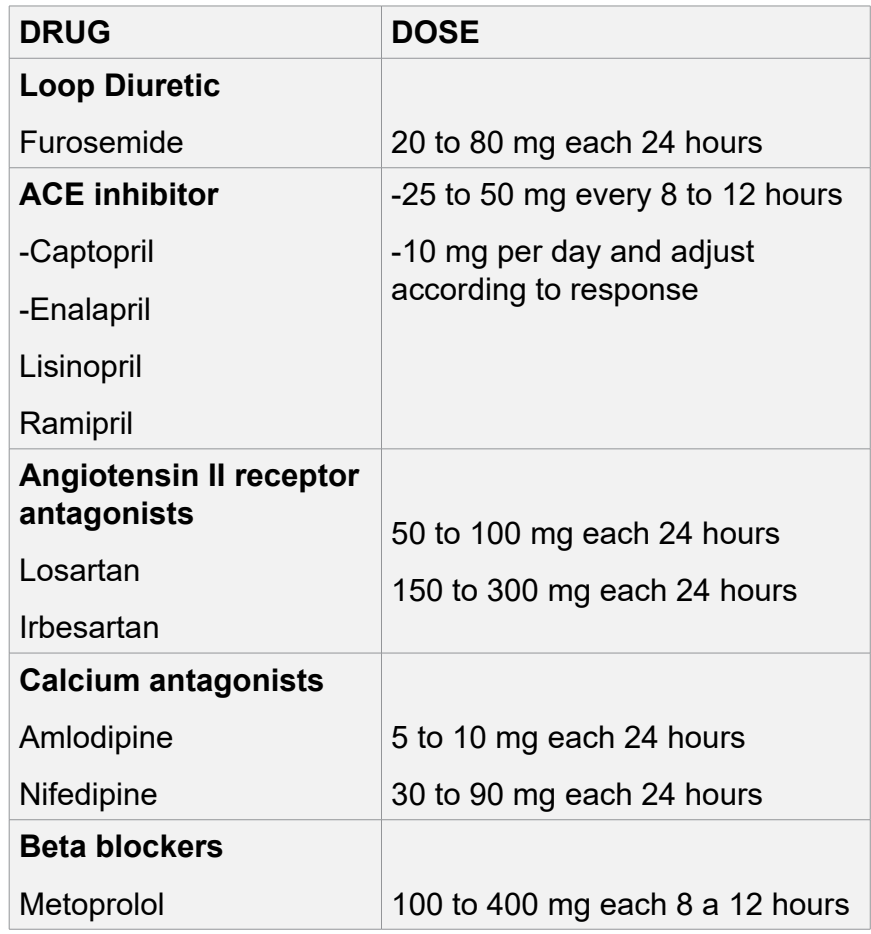




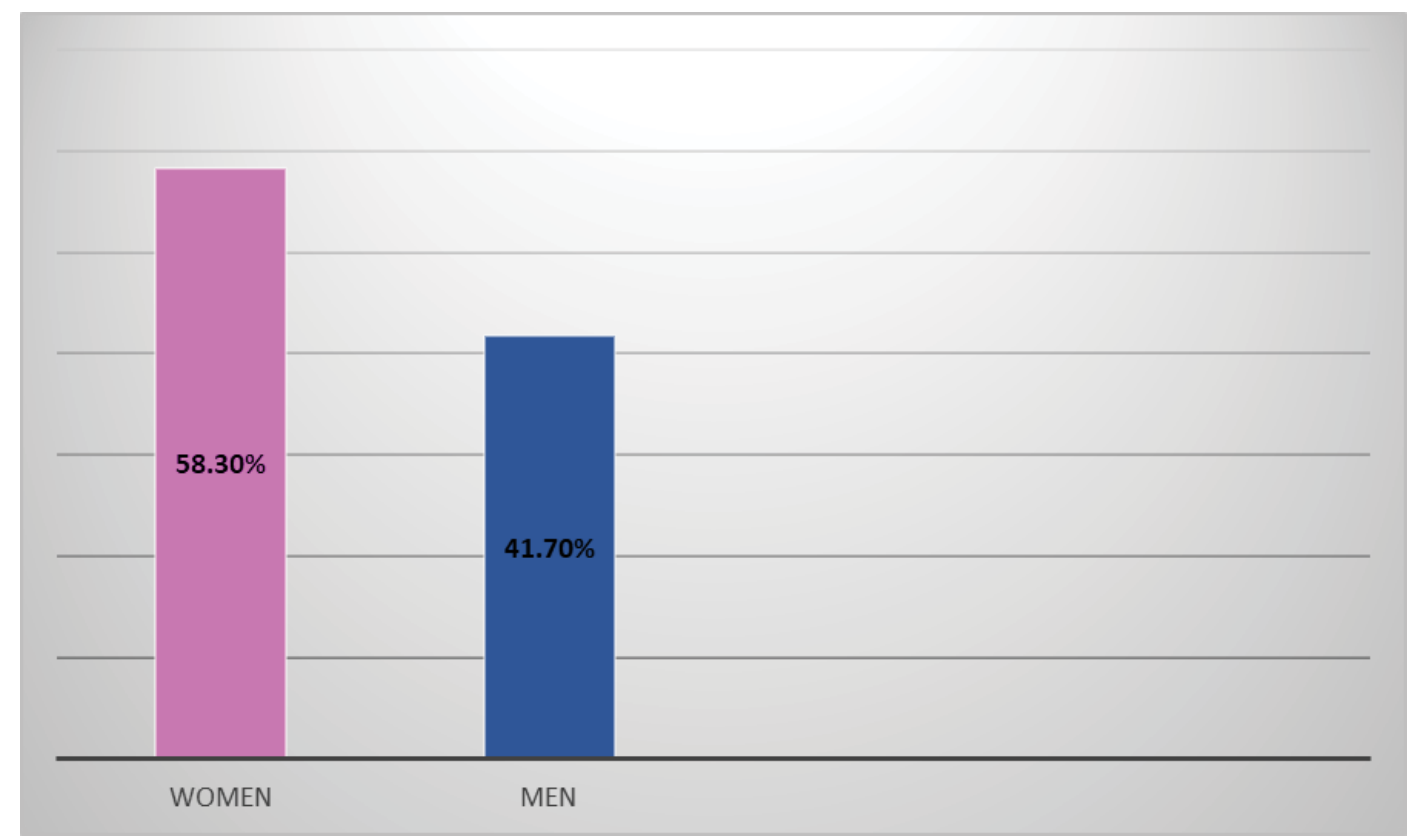

Figure 1: Frequency of patients with hypertensive crisis according to gender.

\section{Referral Criteria}

Patients with hypertensive emergencies require rapid stabilization in the emergency room and later admission to the intensive care unit to continue antihypertensive management and other alterations that have to be resolved, for example in the case of intracerebral hemorrhages that require surgical intervention, or in the case of an ischemic cerebrovascular event that warrants fibrinolysis, among others.

In the case of hypertensive urgency, once it is identified, it warrants medical attention, however, in this case, the time range for BP control is 24 to 48 hours, so it can be performed on an outpatient basis, with careful follow-up in your first-level health care unit.

The patient who goes for evaluation to a first level of care with a diagnosis of emergency-type hypertensive crisis will be referred to a second or third level of care, if possible, channel a peripheral line, administer oxygen therapy in the period in which it is referred to a hospitable area. Oral treatment can be started if the patient's condition allows it.

Similarly, the patient should be referred in case of suspicion of malignant hypertension, as well as if a hypertensive urgency occurs in which, after managing in primary care and after 2-3 hours, values above 200/100 $\mathrm{mmHg}$ persistent.

The transfer of the patient in suitable conditions must be guaranteed. Transfer by ambulance to the nearest hospital service and have a medical team trained in advanced cardiovascular life support [17].

\section{Methods}

Observational, cross-sectional, descriptive study, non-probability sampling type, Sample size calculated based on the finite population formula. Patients referred from the first-level units in the period of august 2019 to July 2020 with a diagnosis of hypertensive crisis were included, where the reason for referral to the emergency service was determined in addition to the clinical characteristics of the patient, blood pressure figure, in addition to determine if it is a hypertensive urgency or emergency (in this case evaluating acute target organ damage).

\section{Study universe}

Emergency service of the Hospital General de Zona \# 50 of the IMSS of San Luis Potosí, Mexico.

\section{Study population}

Adult patients with a diagnosis of hypertensive crisis referred from a first level care unit to the emergency service of the Hospital General de Zona \# 50 of the IMSS of San Luis Potosí, Mexico.

\section{Results}

In our study, a total of 204 referrals were obtained from patients with a diagnosis of hypertensive crisis, of which 119 women (58.3\%) and 85 men (41.7\%) were obtained (Figure 1).

The mean age of the patients was 53.8 years in general, with a minimum age of 19 years and a maximum age of 95 years.

Of the 204 referrals, the majority were hypertensive urgencies with 161 (78.9\%) and 43 (21.1\%) were emergencies.

It was found that in the vast majority of cases of both urgency and hypertensive emergency, patients did not adhere to their usual treatment in a similar percentage, $131(81.4 \%)$ for urgencies and 34 (79.1\%) for emergen- 


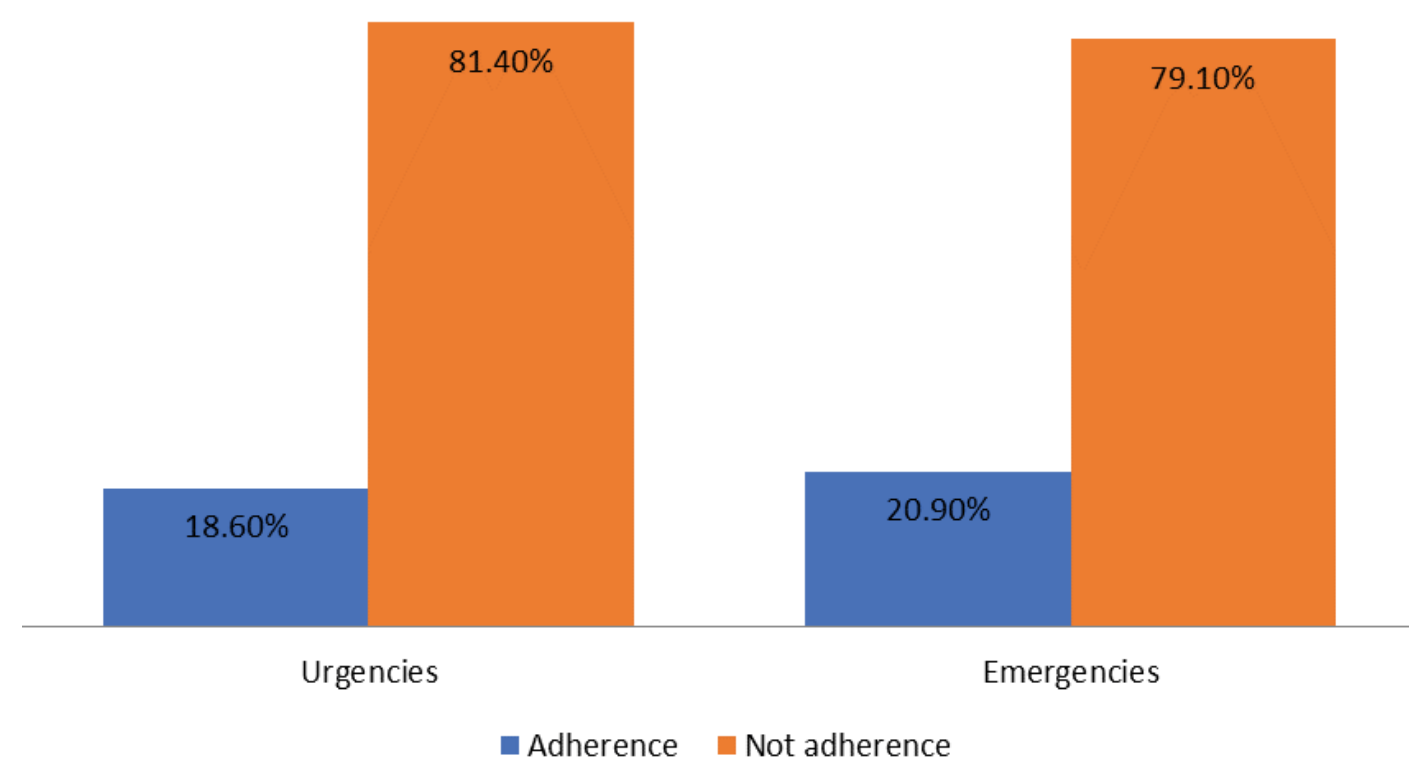

Figure 2: Adherence to habitual antihypertensive treatment in urgency and hypertensive emergency.

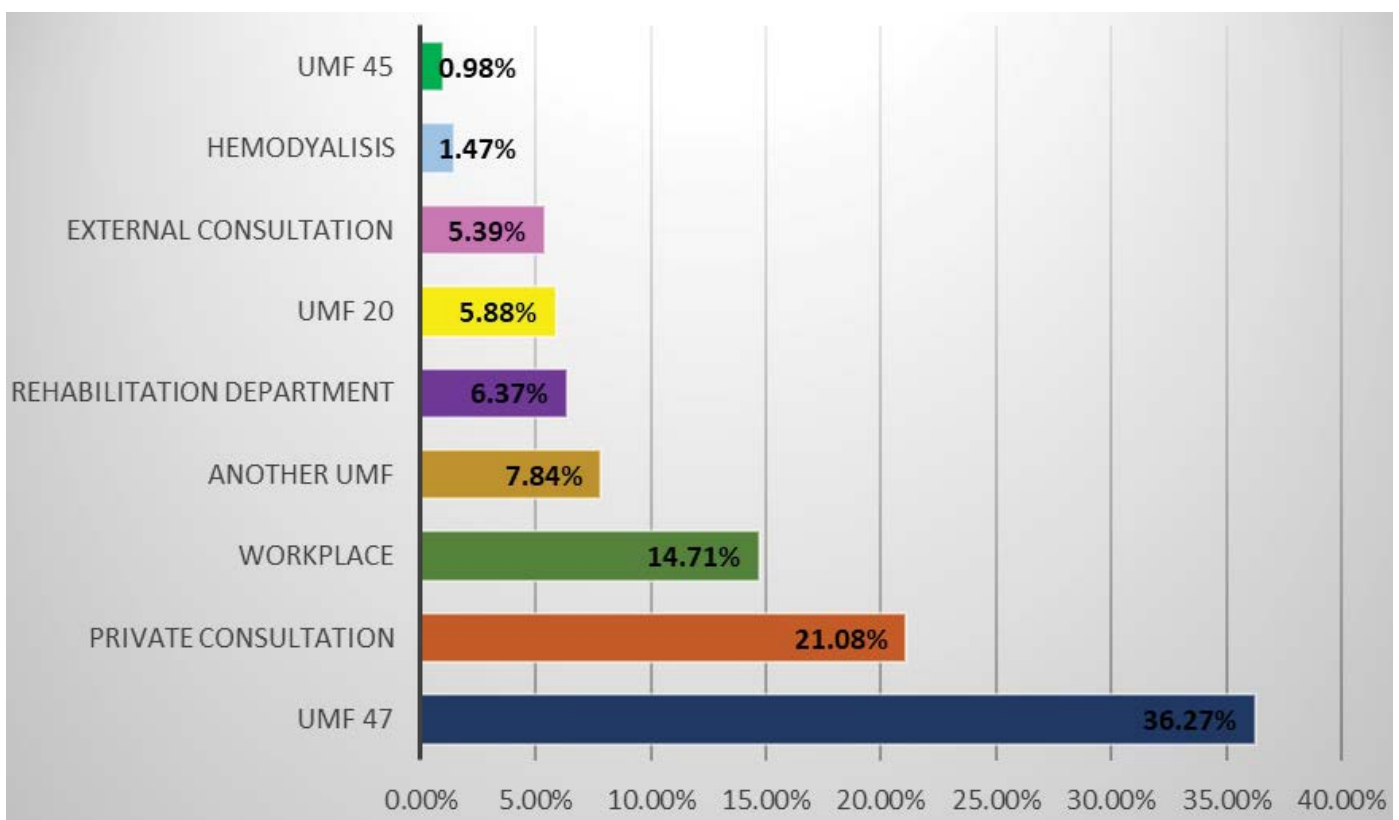

Figure 3: Frequency per referral site.

Table 5: Frequency by type of hypertensive emergency.

\begin{tabular}{|l|l|l|}
\hline EMERGENCY TYPE & FREQUENCY & PERCENTAGE \\
\hline Acute coronary syndrome & 13 & $30.2 \%$ \\
\hline Acute pulmonary edema & 12 & $27.9 \%$ \\
\hline Cerebrovascular accident & 8 & $18.6 \%$ \\
\hline Hypertensive encephalopathy & 6 & $14 \%$ \\
\hline Acute kidney injury & 4 & $9.3 \%$ \\
\hline TOTAL & $\mathbf{4 3}$ & $\mathbf{1 0 0 \%}$ \\
\hline
\end{tabular}

cies (Figure 2).

Regarding the referrals for hypertensive emergencies (43 referrals), which correspond to $21.1 \%$ of the total number of patients, we observed that the most frequent was acute coronary syndrome with 13 patients (30.2\%), followed by acute pulmonary edema with 12 patients (27.9\%), the one with the lowest prevalence was acute kidney injury with only 4 patients, corresponding to $9.3 \%$ (Table 5).

The reference sites in general were registered, where we observed that the highest number of references are from the Unidad de Medicina Familiar (UMF) 47 with 74 


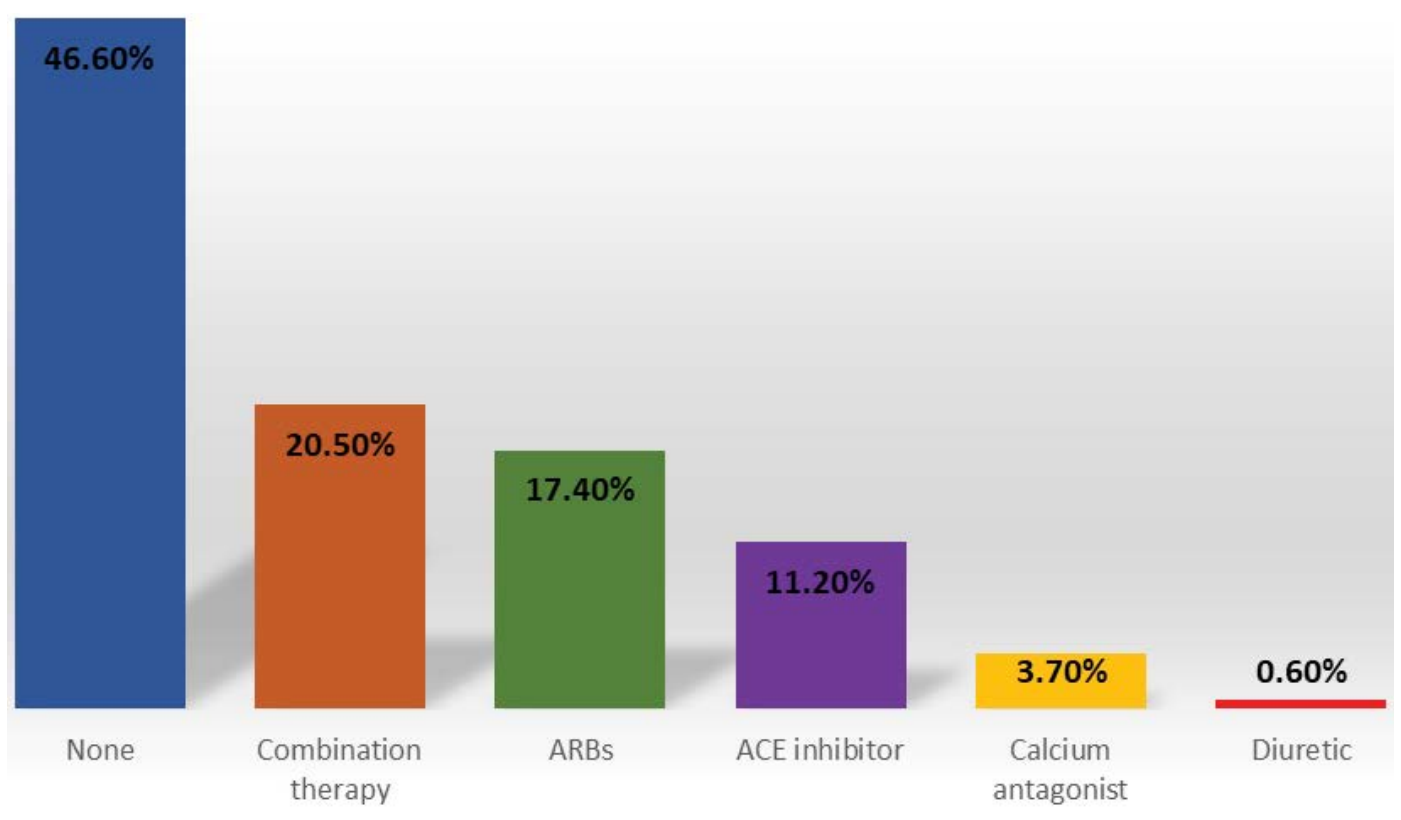

Figure 4: Treatment given at the referral site in cases of hypertensive urgency.

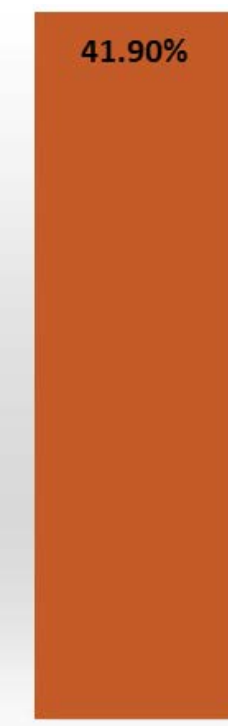

Conbination therapy

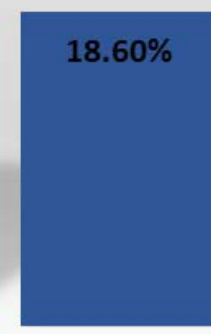

None

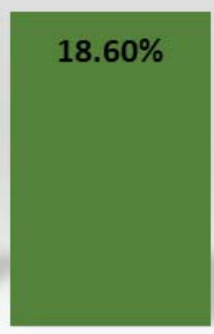

ARBs

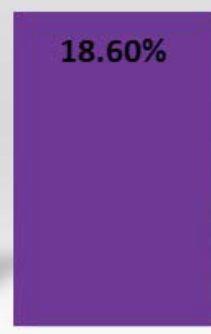

ACE inhibitor
$2.30 \%$

Calcium antagonist

Figure 5: Treatment given at the referral site in cases of hypertensive emergency.

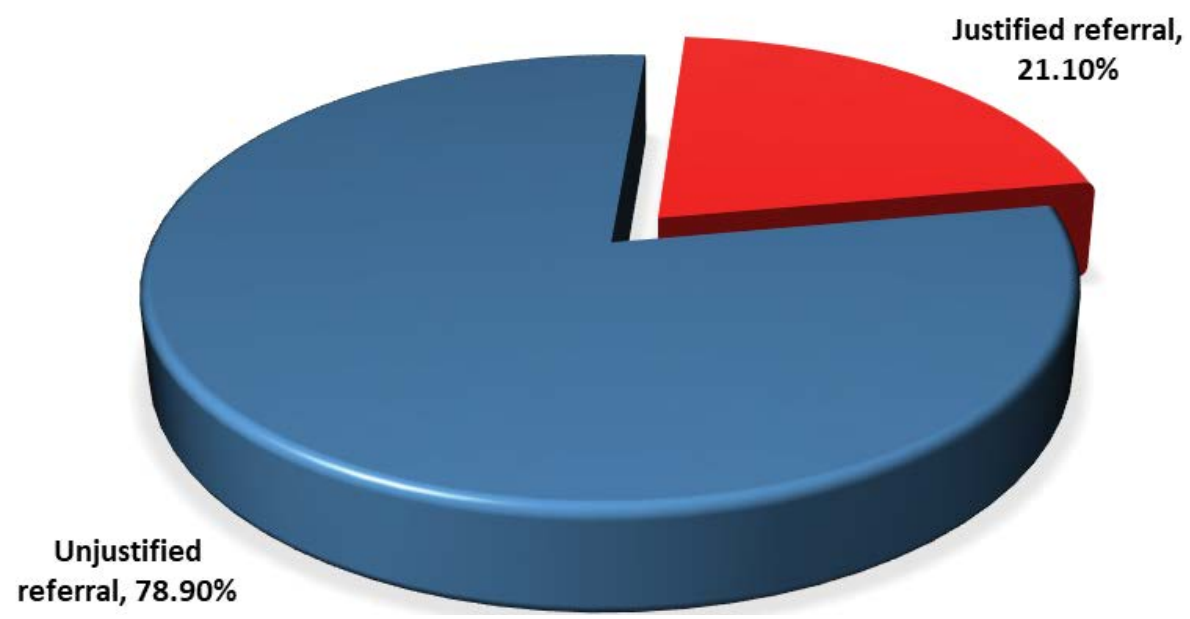

Figure 6: Justified and unjustified referrals of patients with hypertensive crisis. 
(36.27\%), followed by the private medical service with $43(21.08 \%)$, the one with the lowest number of references was UMF 45 with 2 (1\%) (Figure 3).

The antihypertensive treatment given at the referral site for both urgencies and hypertensive emergencies was highly variable, in most hypertensive urgencies no antihypertensive treatment was administered prior to referral to the emergency service, reporting 75 patients $(46.6 \%)$, in the case of emergencies, the most frequent treatment was antihypertensive therapy combined with 18 patients (41.9\%) (Figure 4 and Figure 5).

Therefore, and as the main objective of our study, we obtain that the majority of referrals for hypertensive crisis in first-level units are not justified, since $78.9 \%$ of urgencies are registered and only $21.1 \%$ are emergencies (Figure 6).

\section{Discussions}

The hypertensive crisis, being a complication of HTN, a prevalent pathology in our country and that can cause a state of severity, disability or even death, requires an adequate diagnosis, classification and management depending on the level of care it deserves, it is essential that each doctor from the first to the third level of care knows the fundamental aspects of the hypertension such as its pathophysiology, epidemiology and complications in order to offer an appropriate treatment and avoid damage to any target organ.

In our study, we observed that the majority of referrals from the first-level units with a diagnosis of hypertensive crisis are not justified as they are hypertensive urgency, since of the 204 registered referrals, only $21.1 \%$ (43 referrals) were justified as Hypertensive emergencies in its different variants, the rest, $78.9 \%$ (161 references) were hypertensive urgencies, which were treated in our service being classified as blue or green triage (without urgency or minor urgency) since they did not suffer any type of organ damage target that warranted immediate stabilization, these 161 patients could have been adequately cared for in the first level units from which the referral was made, thus reducing the overload of patients in our service. The relationship of presentation of the types of hypertensive crisis in our study is similar to that mentioned in the national literature.

Adherence to habitual antihypertensive treatment was bad for both groups of patients, with around $80 \%$ of whom did not adhere to treatment for urgencies and emergencies, so this could be one of the main factors causing the crisis hypertensive, in addition to being a situation which prevents an adequate estimate of the effective coverage of the treatment of arterial hypertension in Mexico according to national statistics. It would also be valuable to know the treatment scheme granted in your medical unit to determine if another the triggering factor for hypertensive crisis is a suboptimal dose or antihypertensive drug that is inappropriate for each patient, this being a potential field of research.

The management of patients prior to arrival at the emergency room was inadequate, mainly in the case of hypertensive urgencies, since in most cases (46.6\%) no type of antihypertensive was administered, so it would be important to adhere to the National and international management guidelines currently available. It would be important to determine the reason why this happens, since it could be due to a lack of supplies or medicines in the medical units or if the treating doctor, he does not know the care protocol that must be carried out at present.

There is poor management of the hypertensive crisis in our region, this being a complication of one of the most prevalent diseases in the country and the world, it is necessary to carry out actions such as constant training on the subject of acute and chronic complications of HTN that help reduce this situation, mainly at the first level, which is where patients initially go for medical attention and where their usual antihypertensive treatment is also taken, this in addition to being a benefit for the beneficiary, would help reduce the number of patients who come to a second level emergency room without requiring immediate attention, thus reducing costs and supplies for the institute and improving the time of attention in the service.

\section{Sources of Support}

Funding information is not applicable/no funding was received.

\section{Statement of Equal Author's Contribution}

All the authors in this manuscript made an equivalent contribution to its development.

\section{References}

1. Lopez GAG, Romero BSC, Gracia-Ramos AE, Navarro MC, Alvarado EP (2020) Diagnóstico y tratamiento de las crisis hipertensivas en los tres niveles de atención. Guía de Práctica Clínica: Evidencias y Recomendaciones. Cenetec, México.

2. Rosas M, Palomo S, Borrayo G, Madrid A, Almeida E, et al. (2016) Consenso de Hipertensión Arterial Sistémica en México. Rev Med Inst Mex Seguro Soc 54: 6-51.

3. Hernandez M, Rivera J, Shamah T, Cuevas L, Gómez LM, et al. (2017) Encuesta Nacional de Salud y Nutrición de Medio Camino 2016.

4. Whelton PK, Carey RM, Aronow WS, Casey DE, Collins KJ, et al. (2017) 2017 Guideline for the Prevention, Detection, Evaluation, and Management of High Blood Pressure in Adults. J Am Coll Cardiol: 23976.

5. Williams B, Mancia G, Spiering W, Agabiti Rosei E, Azizi M, et al. (2018) 2018 ESC/ESH Guidelines for the management of arterial hypertension: The Task Force for the management of arterial hypertension of the European Society of Cardiology and the European Society of Hypertension. J Hypertens 36: 1953-2041. 
6. Zipes DP, Libby P, Bonow RO, Mann DL, Tomaselli GF (2019) Hipertensión sistémica: Tratamiento. Braunwald. Tratado de cardiología. Texto de medicina cardiovascular. (11 ${ }^{\text {th }}$ edn), Elsevier, 928-959.

7. Mendoza C, Rosas M, Lomelí C, Lorenzo J, Méndez A, et al. (2008) Elevación extrema de la presión arterial (crisis hipertensiva): Recomendaciones para su abordaje clínico-terapéutico. Archivos de cardiología de México 78: 7481.

8. Wagner P (2010) Fisiopatología de la hipertensión arterial. An Fac med 71: 225-229.

9. Albaladejo C, Sobrino J, Vázquez S (2014) Crisis hipertensivas: Seudocrisis, urgencias y emergencias. Hipertens Riesgo Vasc 31: 132-142.

10. Sinert R, Peacock PR (2018) Chapter 68 Acute coronary syndrome. In: Walls RM, Hockberger RS, Gausche M, Rosen's emergency medicine: Concepts and clinical practice. $\left(9^{\text {th }}\right.$ edn), Elsevier, Philadelphia, PA, 891-928.

11. Morales E, González R, Praga M (2011) Situación actual de la hipertensión arterial maligna. Hipertens Riesgo Vasc 28: 79-82.
12. (2018) Chapter 75 Aortic dissection. In: Walls RM, Hockberger RS, Gausche M, Rosen's emergency medicine: Concepts and clinical practice. $\left(9^{\text {th }}\right.$ edn), Elsevier, Philadelphia, PA, 1021-1026.

13. Baumann BM (2016) Systemic Hypertension. In: Tintinalli JE, Stapczynski JS, Ma OJ, Yealy DM, Meckler GD, et al. Tintinalli's Emergency Medicine: A Comprehensive Study Guide. ( $8^{\text {th }}$ edn), The McGraw Hill Companies, NY, 399-409.

14. Sinert R, Peacock PR (2016) Acute kidney injury. In: Tintinalli JE, Stapczynski JS, Ma OJ, Yealy DM, Meckler GD, et al. Tintinalli's Emergency Medicine: A Comprehensive Study Guide. ( $8^{\text {th }}$ edn), The McGraw Hill Companies, NY, 575-581.

15. (2018) Chapter 74 Hypertension. In: Walls RM, Hockberger RS, Gausche M, Rosen's emergency medicine: Concepts and clinical practice. ( $9^{\text {th }}$ edn), Elsevier, Philadelphia, PA, 1007-1020.

16. Instituto Mexicano del Seguro Social (2014) Diagnóstico y Tratamiento de la Hipertensión Arterial en el Primer Nivel de Atención. México.

17. Ribera M, Caballero I (2014) Crisis hipertensiva. AMF 10: 89-94. 